Journal homepage:www.jurnal.stiebi.ac.id

ISSN 0126-1991 E-ISSN 2656-4114

\title{
ANALISIS PERAMALAN HASIL PRODUKSI GITAR DENGAN MENGGUNAKAN MODEL APX500II BULAN JANUARI 2015 PADA PT. YAMAHA MUSIC MANUFACTURING INDONESIA (METODE FORECASTING DAN QM FOR WINDOWS)
}

\author{
Dewi Haryanti \\ Alumni STIE Bisnis Indonesia \\ haryati@yahoo.com \\ Syahnan Phalipi \\ Dosen STIE Bisnis Indonesia, Jakarta \\ syahnan phalipi@stiebi.ac.id \\ Muhammad Ichwan Hamzah \\ Dosen STIE Bisnis Indonesia, Jakarta \\ mcham@stiebi.ac.id
}

\begin{abstract}
This research is in the field of marketing management. Type of this research is a quantitative descriptive study which is a research method used to analyze the data in descriptive statistics, while the method used is quantitative forecasting method (forecasting). The purpose of the study was to determine the production guitars using APX500II model's in January 2015 at PT. Yamaha Music Manufacturing Indonesia with forecasting method and QM for Windows. So the production result of guitar same with marketing demand and wasn't over production. Also to determine the value of MAD and MSE corresponding to predict the results of guitar in January 2015. Location of the research conducted in PT. Yamaha Music Manufacturing Indonesia. The study was conducted on December $8^{\text {th }} 2014$ until January $9^{\text {th }} 2015$ for one month. The results showed that of the six forecasting methods used, the lowest value of MAD is 391.0755 and MSE is 246,291.6152. So it can be obtained that the value of forecasting production results using APX500II model's for January 2015 amounting to 1,068.4695 units.
\end{abstract}

Keywords: Forecasting, Production, Guitar.

Abstrak: Penelitian ini merupakan penelitian di bidang manajemen pemasaran. Jenis penelitian ini adalah penelitian deskriptif kuantitatif yang merupakan metode penelitian yang digunakan untuk menganalisis suatu data statistik secara deskriptif, sedangkan metode yang digunakan adalah metode peramalan kuantitatif (forecasting). Tujuan penelitian adalah dapat mengetahui peramalan produksi gitar model APX500II bulan Januari 2015 pada PT. Yamaha Music Manufacturing Indonesia menggunakan metode forecasting dan QM for Windows. Sehingga hasil produksi gitar sesuai dengan permintaan pasar dan tidak terjadi pemborosan atau kerugian akibat produksi berlebih. Serta dapat mengetahui nilai MAD dan MSE yang paling sesuai untuk meramalkan hasil produksi gitar bulan Januari 2015. Lokasi penelitian dilakukan pada PT. Yamaha Music Manufacturing Indonesia. Penelitian dilaksanakan pada 08 Desember 2014 sampai 09 Januari 2015 selama satu bulan. Hasil penelitian menunjukkan bahwa dari ke enam metode peramalan yang digunakan, nilai MAD dan MSE yang paling rendah yaitu nilai MAD sebesar 391,0755 dan MSE 246.291,6152. Maka dapat diperoleh nilai peramalan hasil produksi gitar model APX500II untuk bulan Januari 2015 sebesar 1.068.4695 unit.

Kata Kunci: Peramalan, Produksi, Gitar. 


\section{Pendahuluan}

Seiring dengan perkembangan musik dan alat musik sebagai penunjangnya, menjadikan persaingan antar perusahaan produsen alat musik meningkat. Persaingan tersebut terdorong dari upaya untuk memenuhi kebutuhan masyarakat, khususnya pemenuhan hasrat bermusik atau memainkan alat musik dengan membuat produk alat musik yang berkualitas. Berkaitan dengan usaha pembuatan alat musik baik alat musik tradisional maupun modern, gitar merupakan salah satu alat musik yang menjadi target produksi bagi perusahaan produsen alat musik. Hal tersebut dikarenakan ragam jenis gitar dan harga yang relatif terjangkau oleh semua kalangan, menjadikan permintaan dan minat beli masyarakat terhadap gitar selalu mengalami peningkatan dari tahun ke tahun.

Sebagai salah satu perusahaan produsen gitar, PT. YMMI (Yamaha Music Manufacturing Indonesia) yang berlokasi di Kawasan Industri Pulogadung, Jakarta Timur, saat ini memproduksi dua jenis gitar yaitu gitar akustik dan gitar elektrik. Gitar akustik terdiri dari beberapa model yaitu APX500II, APXT2, CPX500II, FG, FX, FS, CG, CS, GL, dan JR. Sedangkan model gitar elektrik terdiri dari BB, RBX, RGX, TRB, TRBX, PAC, EG, TG, TRG, VARIAX, dan silent guitar (SLG). Dari berbagai model tersebut, PT. Yamaha Music Manufacturing Indonesia mempunyai produk unggulan dari jenis akustik gitar yang menjadi prioritas produksi yaitu gitar model APX terutama seri 500II atau disebut APX500II. Diantara kelebihannya adalah suara jernih, bentuk elegant dan keberagaman warna cat body yang menarik sehingga permintaan pasar terhadap model APX500II dari tahun ke tahun selalu mengalami peningkatan. Penentuan jumlah produksi berdasarkan ramalan penjualan adalah penting, agar tidak menimbulkan pemborosan atau kerugian akibat produksi yang berlebih maupun ketidaktercapaian target produksi karena lemahnya faktor-faktor produksi yang ada sehingga semua produk dapat dipasarkan. Perusahaan perlu memperkirakan capaian hasil produksi berdasarkan kemampuan perusahaan agar jumlah unit yang akan diproduksi berbanding lurus dengan permintaan pasar. Sebab ketidakmampuan perusahaan dalam mencapai target permintaan, sama dengan memberikan kesempatan kepada perusahaan sejenis untuk masuk dan menguasai pasar.

Forecasting merupakan seni atau ilmu untuk meramalkan kejadian di masa depan, yang dilakukan dengan mengambil data masa lalu dan menempatkannya ke masa depan dengan suatu bentuk model sistematis. Metode forecasting ini terdiri dari enam cara pengerjaan yaitu metode regresi linier (linear regression), metode penghalusan eksponensial dengan tren (exponential smoothing with trend), penghalusan eksponensial (exponential smoothing), rata-rata tertimbang (weighted moving average), rata-rata bergerak (moving average), dan metode naif (naive method). Dari berbagai metode peramalan tersebut perusahaan dapat menemukan metode yang paling tepat untuk meramalkan hasil produksi pada periode yang akan datang. merumuskan masalah yang akan dibahas metode yang tepat yang akan digunakan oleh perusahaan.

\section{Landasan Teori \\ Produksi}

Menurut Fahmi (2014:2) "Produksi adalah sesuatu yang dihasilkan oleh perusahaan baik berbentuk barang (goods) maupun jasa (service) dalam suatu periode waktu yang selanjutnya dihitung sebagai nilai tambah bagi perusahaan." Kemudian menurut Sofjan (2004:27) "Konsep produksi adalah suatu orientasi manajemen yang menganggap bahwa konsumen akan menyenangi produk-produk yang telah dapat tersedia dan dapat dibeli." Konsep ini berorientasi pada produksi dimana para manajer perusahaan memusatkan upaya untuk mencapai efisiensi yang tinggi dan distribusi yang luas.

\section{Produk}

Gitosudarmo dalam Sunyoto (2014:69) menyatakan bahwa "Produk adalah segala sesuatu yang diharapkan dapat memenuhi kebutuhan manusia ataupun organisasi." Sementara menurut Kotler (2009:34) "Produk sesuatu yang dapat ditawarkan ke pasar untuk diperhatikan, dimiliki, dipakai atau 
dikonsumsikan sehingga dapat memuaskan keinginan atau kebutuhan." Kemudian menurut Irawan dalam Sunyoto (2014:69) "Produk adalah sesuatu yang ditawarkan dan dapat memuaskan keinginan dan kebutuhan konsumen."

\section{Gitar}

Menurut Satria (2014:4) "Gitar adalah sebuah alat musik berdawai yang dimainkan dengan cara dipetik, umumnya menggunakan jari maupun plectrum (alat bantu petik)." Gitar terbentuk atas sebuah bagian badan pokok dengan bagian leher yang padat dan bagian kepala sebagai tempat ikat senar. Tubuh gitar terdiri dari tiga bagian utama yaitu kepala, leher dan badan.

\section{Penelitian Terdahulu}

Menurut pendapat Alfatiyah dan Mahyar (2013) dari hasil penelitian yang telah dilaksanakan mengenai perencanaan produksi dengan menggunakan teknik peramalan metode time series pada proses produksi minyak telon ukuran $100 \mathrm{ml}$ di PT. Merpati Mahardika, dapat disimpulkan bahwa:

1. Model rata-rata bergerak (moving averages model) dengan MA (4) didapatkan tingkat produksinya adalah 144.978 botol dan MAD sebesar 29.096,25. Dan dengan MA(5) didapatkan tingkat produksinya adalah 144.811 botol dan MAD dengan nilai 24.469,48.

2. Model rata-rata bergerak terbobot (weighted moving averages model) dengan WMA (4) didapatkan nilai produksinya adalah 147.293 botol dan MAD sebesar 25.929, dan dengan WMA (5) didapatkan tingkat produksinya adalah 146.466 botol dan MAD dengan nilai 23.918,40.

3. Model pemulusan eksponensial (exponential smoothing model) dengan ES $(\alpha=0,99)$ didapatkan tingkat produksinya adalah 145.378 botol dan MAD dengan nilai 41.803,12.

4. Model analisis garis kecenderungan (trend line analysis model) dengan persamaan garis lurus $\mathrm{Ft}=\mathrm{a}+\mathrm{bt}=102.308,85+4.736 \mathrm{t}$, didapatkan tingkat produksinya adalah 163.877 botol dan MAD dengan nilai 39.013,47.

5. Model pemulusan eksponensial dengan mempertimbangkan kecenderungan (exponential smoothing with trend model) dengan nilai alfa 0,99 dan nilai beta 0,3 didapatkan tingkat produksinya adalah 146.319 botol dan MAD dengan nilai 49.018,25.

6. Model analisis garis kecenderungan dengan mempertimbangkan pengaruh musiman (seasional variation) dan menggunakan persamaan garis lurus yaitu:

$\mathrm{Ft}=\mathrm{a}+\mathrm{bt}=102.308,85+4.736 \mathrm{t}$, didapatkan tingkat produksinya adalah 163.877 botol dan MAD dengan nilai 74.228,9.

Dari ke enam model peramalan yang digunakan, nilai MAD yang paling rendah adalah model peramalan rata-rata bergerak terbobot per lima bulan yaitu mempunyai nilai 23.918,40, maka dapat diperoleh nilai forecasting untuk bulan September 2013 adalah 146.466 botol ukuran $100 \mathrm{ml}$. Menurut pendapat Lengkey, dkk (2014) penelitian ini merupakan penelitian di bidang manajemen operasional/produksi. Jenis penelitian ini merupakan penelitian deskriptif yang merupakan metode penelitian yang digunakan untuk menganalisis suatu data secara deskriptif. Tujuan penelitian adalah untuk mengetahui perencanaan produksi dalam menentukan kuantitas produk yang seharusnya diproduksi di perusahaan CV. Fani Jaya. Kesimpulan dari penelitian sebagai berikut:

a. Produksi kecap CV. Fani Jaya setiap bulannya dapat dihitung menggunakan formula: Y, Untuk tahun 2014 rata-rata setiap bulan produksi kecap perusahaan adalah sebanyak delapan puluh empat ribu sembilan ratus delapan belas botol kecap per bulannya atau tiga ribu lima ratus tiga puluh delapan krat kecap per bulannya.

b. Produksi kecap tahunan dari perusahaan CV. Fani Jaya dapat diperoleh menggunakan formula: Y. Dimana rata-rata produksi tahunan selama empat tahun ke depan adalah delapan 
ratus enam puluh tiga ribu botol kecap per tahun atau tiga puluh lima ribu sembilan ratus lima puluh sembilan krat kecap per tahun.

Menurut pendapat Sarjono (2011) software QM for Windows adalah sebuah software yang dirancang untuk melakukan perhitungan yang diperlukan pihak manajemen untuk mengambil keputusan di bidang produksi dan pemasaran. Software ini dirancang oleh Howard J. Weiss tahun 1996 untuk membantu manager produksi khususnya dalam menyusun perkiraan dan anggaran untuk produksi bahan baku menjadi produk jadi atau setengah jadi dalam proses pabrikasi. Hasil perhitungan ternyata hanya lima metode saja yang bisa dihitung menggunakan program Minitab, yaitu exponential smoothing, exponential smoothing with trend, linear regression atau least squares, moving average dan trend analysis (regress over time), sedangkan apabila menggunakan program QM for Windows bisa sebelas metode forecasting, tetapi dalam penelitian ini baik Minitab dan $Q M$ hanya lima metode forecasting yang dipakai, sehingga terlihat perbedanannya. Dari 5 metode forecasting, ternyata metode linear regression/least squares dan trend analysis (regress over time) menghasilkan MAD dan MSE yang sama dan terkecil, yaitu 9,2655 dan 127,3574, sehingga hasil forecasting sebesar 255 botol, inilah yang akan digunakan untuk perhitungan selanjutnya. Menurut pendapat Panjaitan, dkk (2013) makalah ini dilakukan peramalan aluminium batangan dengan menggunakan model arima, berdasarkan hasil analisa di atas dapat diambil kesimpulan sebagai berikut: model peramalan yang digunakan untuk meramalkan hasil produksi aluminium batangan untuk 24 periode ke depan adalah:

$\mathrm{Y}_{\mathrm{t}}=\mathrm{Y}_{\mathrm{t}}-0,4890 \mathrm{Y}_{\mathrm{t}-1}-2,393 \mathrm{Y}_{\mathrm{t}-2}+5,814 \mathrm{Y}_{\mathrm{t}-3}+0,6707 \mathrm{Y}_{\mathrm{t}-4}+0,4762 \mathrm{Y}_{\mathrm{t}-5}+\mathrm{Y}_{\mathrm{t}-12}+0,4890 \mathrm{Y}_{\mathrm{t}-13}+0$, $2393 \mathrm{Y}_{\mathrm{t}-14}-0,5814_{\mathrm{Yt}-15}+0,4762 \mathrm{Y}_{\mathrm{t}-16}-0,4762 \mathrm{Y}_{\mathrm{t}-17}+\mathrm{et}+1,431 \mathrm{et}-1+1,4455 \mathrm{et}-2+0,5737 \mathrm{et}-3-0$, 7085 et $-12-0,4065$ et $-13-1,0241$ et $-14+0,065$ et -152 . Rata-rata hasil produksi aluminium batangan tahun 2012 dan 2013 adalah 19.548 ton dengan standar deviasi 745,2.

\section{Kerangka Pikir}

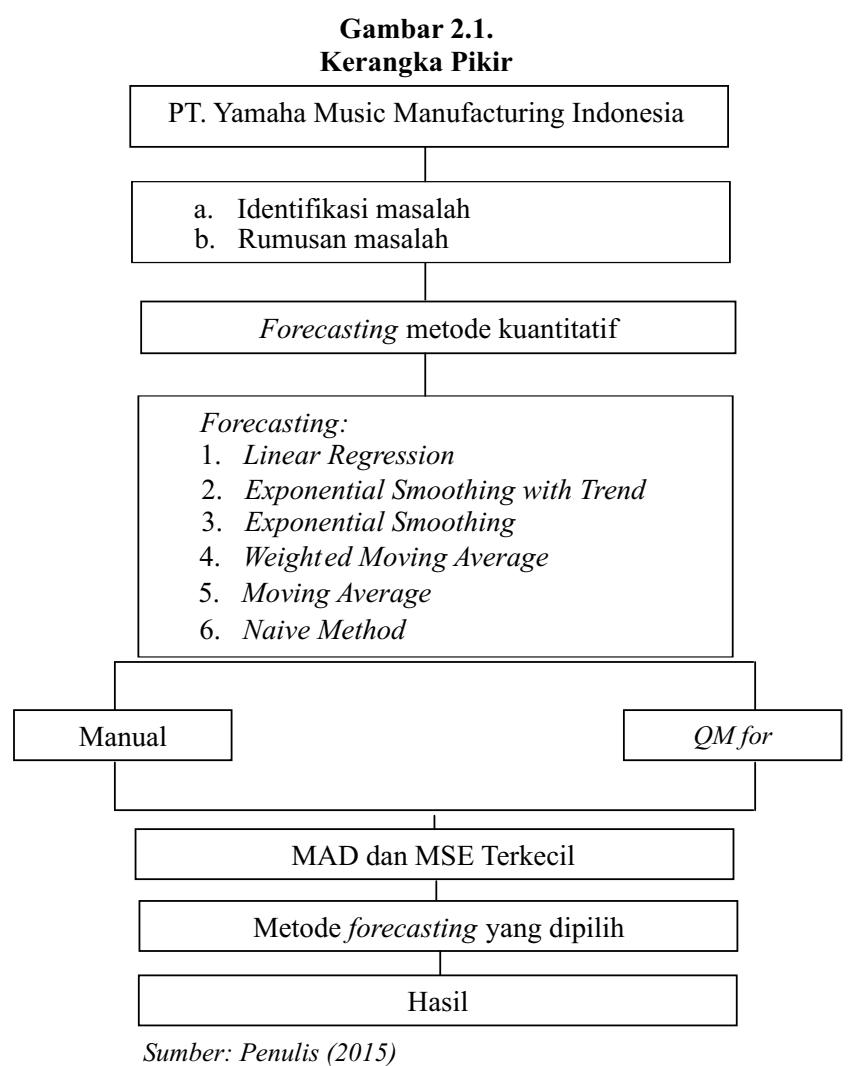




\section{Metodologi Penelitian}

Metode penelitian merupakan cara ilmiah untuk mendapatkan data yang memiliki tujuan dan kegunaan tertentu. Data yang diperoleh melalui penelitian adalah data yang teramati yang mempunyai kriteria yaitu valid dan mempunyai derajat ketepatan antara data yang sesungguhnya terjadi pada objek dengan data yang dikumpulkan oleh peneliti. Peramalan kuantitatif(forecasting) adalah penelitian dengan menggunakan data-data kuantitatif pada masa lalu. Jadi penelitian deskriptif kuantitatif adalah metode penelitian yang digunakan untuk menganalisis suatu data statistik secara deskriptif dengan menggunakan data masa lalu yang berupa angka-angka. Untuk memperoleh data primer, peneliti melakukan observasi dan wawancara secara langsung dengan nara sumber (pimpinan produksi PT.YMMI) untuk mendapatkan data yaitu data hasil produksi gitar model APX500II dari bulan Januari sampai Desember tahun 2014 dan data mengenai profil perusahaan. Datanya adalah sebagai berikut:

Tabel 3.1.

Data Hasil Produksi Gitar Model APX500II Tahun 2014

\begin{tabular}{l|c|c}
\hline Bulan (2014) & Periode & $\begin{array}{c}\text { Hasil produksi } \\
\left(\mathrm{Y}_{\mathrm{t}}\right)\end{array}$ \\
\hline Januari & 1 & 1.377 \\
\hline Februari & 2 & 2.432 \\
\hline Maret & 3 & 2.320 \\
\hline April & 4 & 3.087 \\
\hline Mei & 5 & 1.743 \\
\hline Juni & 6 & 1.912 \\
\hline Juli & 7 & 1.187 \\
\hline Agustus & 8 & 1.217 \\
\hline September & 9 & 1.414 \\
\hline Oktober & 10 & 1.556 \\
\hline November & 11 & 1.714 \\
\hline Desember & 12 & 7.81 \\
\hline Jumlah & & 20.740 \\
\hline
\end{tabular}

Sumber: PT. YMMI (2015)

\section{Teknik Pengolahan Data Dan Analisis Data}

Metode analisis yang digunakan dalam penelitian ini adalah analisis forecasting. Analisa forecasting digunakan untuk menjawab perumusan (T-1) yaitu mengetahui peramalan hasil produksi gitar model APX 500II bulan Januari 2015 pada PT. Yamaha Music Manufacturing Indonesia. (T-2) yaitu mengetahui metode peramalan (forecasting) yang paling efektif digunakan oleh perusahaan untuk meramalan hasil produksi gitar model APX500II bulan Januari 2015 pada PT. Yamaha Music Manufacturing Indonesia, dan (T-3) yaitu mengetahui nilai MAD dan MSE yang paling sesuai untuk meramalkan hasil produksi gitar model APX500II bulan Januari 2015 pada PT. Yamaha Music Manufacturing Indonesia. Dalam analisa forecasting dilakukan dengan perhitungan secara manual dan menggunakan program $Q M$ for Windows. Program $Q M$ for Windows yang akan digunakan dalam penelitian ini adalah $Q M$ versi 2.2. Pada program ini peneliti akan lebih mudah untuk 
mendapatkan hasil peramalan yang diinginkan, dengan cara memasukkan data-data yang akan diteliti kemudian disesuaikan dengan metode yang akan digunakan. Seperti pada perhitungan manual, maka untuk mendapatkan hasil yang sama sebagai pembanding, metode yang digunakan untuk perhitungan menggunakan QMfor Windows adalah:

1. Linear regression

2. Exponential smoothing with trend

3. Exponential smoothing

4. Weighted moving average

5. Moving average

6. Naivemethod

\section{Analisis Dan Pembahasan}

Berdasarkan data yang diperoleh dari PT. Yamaha Music Manufacturing Indonesia mengenai hasil produksi gitar dengan menggunakan model APX500II dari bulan Januari sampai Desember tahun 2014, maka dapat diramalkan atau diperkirakan hasil produksi gitar model APX500II untuk bulan Januari 2015. Berikut ini data hasil produksi per sub model gitar APX500II secara keseluruhan dari bulan Januari sampai Desember 2014 PT. Yamaha Music Manufacturing Indonesia:

Perhitungan manual menggunakan metode regresi linier dengan $Y=a+b x$ :

1. Cara menghitung nilai b:

$$
\begin{aligned}
& \mathrm{b}=\frac{\sum x y-n \bar{x} \bar{y}}{\sum x^{2}-n \bar{x}} \\
& \mathrm{~b}=\frac{\mathrm{n} \times \sum\left(\mathrm{X}_{\mathrm{i}}\right)\left(\mathrm{Y}_{\mathrm{i}}\right)-\sum \mathrm{X}_{\mathrm{i}} \times \sum\left(\mathrm{Y}_{\mathrm{t}}\right)}{\mathrm{n} \times \sum\left(\mathrm{X}_{\mathrm{i}}\right)^{2}-\left(\sum \mathrm{X}_{\mathrm{i}}\right)^{2}} \\
& \mathrm{~b}=\frac{12 \times 120.293-78 \times 20.740}{12 \times 650-(78)^{2}} \\
& \mathrm{~b}=\frac{1.443 .516-1.617 .720}{7800-6084} \\
& \mathrm{~b}=\frac{-174.204}{1.716} \\
& \mathrm{~b}=-101,5175
\end{aligned}
$$

2. Cara menghitung nilai a:

$$
\begin{aligned}
\mathrm{a} & =\bar{y}-\bar{b} \bar{x} \\
\mathrm{a} & =\frac{\sum Y t}{n}-b \times \sum X i \div n \\
\mathrm{a} & =20.740: 12-(-101,5175) \times 78: 12 \\
\mathrm{a} & =1.728,3333-(-659,8637) \\
\mathrm{a} & =1.728,3333+659,8637 \\
\mathrm{a} & =2.388,1970
\end{aligned}
$$

3. Cara menghitung $\mathrm{Y}_{13}$ atau Forecast Januaritahun 2015:

$$
\begin{aligned}
& \mathrm{Y}=\mathrm{a}+\mathrm{bx} \\
& \mathrm{Y}=2.388,1970+(-101,5175) \mathrm{x} \\
& \mathrm{Y}_{13}=2.388,1970+(-101,5175) 13
\end{aligned}
$$


$\mathrm{Y}_{13}=2.388,1970-1.319,7275$

$\mathrm{Y}_{13}=1.068,4695$

3. Cara menghitung MAD dan MSE:

$$
\begin{aligned}
\text { MAD } & =\frac{\sum|Y t-F t|}{n} \\
& =4.692,9058: 12 \\
& =391,0755 \\
\text { MSE } & =\frac{\sum|Y t-F t|^{2}}{n} \\
& =2.955 .499,3828: 12 \\
& =246.291,6152
\end{aligned}
$$

Dari perhitungan manual didapatkan nilai peramalan hasil produksi gitar dengan menggunakan model APX500II bulan Januari 2015 atau $\mathrm{Y}_{13}$ adalah sebesar 1.068,4695 unit. Apabila dibulatkan menjadi 1.068 gitar. Nilai MAD atau kesalahan peramalannya adalah 391,0755 sedangkan nilai MSE nya sebesar 246.291,6152. Apabila dibulatkan MAD sebesar 391 dan MSE sebesar 246.292.

\section{Perhitungan Menggunakan QMfor Windows}

Software QM for Windows merupakan sebuah paket software untuk teknik kuantitatif yang dikembangkan oleh Professor Howard J. Weiss tahun 1996. Software ini berbasiskan menu dan sangat mudah digunakan bahkan oleh pengguna yang tidak mempunyai pengalaman komputer. Software QM for Windows yang digunakan pada penelitian ini adalah QM versi 2.2. Berikut hasil perhitungan peramalan hasil produksi gitar model APX500II pada bulan Januari 2015 dengan menggunakan enam metode forecasting yang terdiri dari:

\section{Metode Regresi Linier (Linear Regression Method)}

Berikut hasil perhitungan menggunakan QM for Windows dengan metode linear regression:

Tabel 4.1

Forecasting Result Linear Regression Method

\begin{tabular}{|l|r|r|r}
\hline Measure & Value & Future Period & Forecast \\
\hline Error Measures & & 13. & $1,068.469$ \\
\hline Bias (Mean Error) & 0.0001 & 14. & 966.952 \\
\hline MAD (Mean Absolute Deviation) & 391.0746 & 15. & 865.4345 \\
\hline MSE (Mean Squared Error) & $246,291.6$ & 16. & 763.917 \\
\hline Standard Error (denom=n-2=10) & 543.645 & 17. & 662.3995 \\
\hline Regression line & & 18. & 560.882 \\
\hline Demand(y) = 2388.197 & & 19. & 459.3645 \\
\hline$-101.5175 *$ Time(x) & & 20. & 357.847 \\
\hline Statistics & & 21. & 256.3295 \\
\hline Correlation coefficient & -0.5768 & 22. & 154.812 \\
\hline Coefficient of determination $\left(\mathrm{r}^{\wedge} 2\right)$ & 0.3327 & 23. & 53.2945 \\
\hline Forecast & & 24. & -48.223 \\
\hline $\mathrm{x}=13$ & $1,068.469$ & 25. & -149.7405 \\
\hline
\end{tabular}

Sumber: QM for Windows (2015) 
Tabel 4.2.

Result and Error Analysis Linear Regression Method

\begin{tabular}{|c|c|c|c|c|c|c|c|c|}
\hline & Demand(y) & Time(x) & $x^{\wedge} 2$ & $x^{*} y$ & Forecast & Error & Enror & Error'2 \\
\hline January & $1,377$. & 1. & 1. & 1,377 . & $2,286.679$ & -909.6794 & 909.6794 & $27,516.7$ \\
\hline February & 2,432 . & 2. & 4. & 4,864 . & $2,185.162$ & 246.8379 & 246.8379 & $0,928.95$ \\
\hline March & 2,320 . & 3. & 9. & 6,960 . & $2,083.645$ & 236.3555 & 236.3555 & $5,863.91$ \\
\hline April & 3,087 . & 4. & 16. & 12,348 . & $1,982.127$ & $1,104.873$ & $1,104.873$ & $220,745$. \\
\hline May & 1,743 . & 5. & 25. & 8,715 . & $1,880.609$ & -137.6095 & 137.6095 & $8,936.37$ \\
\hline June & 1,912 . & 6. & 36. & 11,472 . & $1,779.092$ & 132.908 & 132.908 & $7,664.53$ \\
\hline July & 1,187 . & 7. & 49. & 8,309 . & $1,677.574$ & -490.5745 & 490.5745 & $40,663.3$ \\
\hline August & 1,217 . & 8. & 64. & 9,736 . & $1,576.057$ & .359 .057 & 359.057 & $28,921.9$ \\
\hline September & 1,414 . & 9. & 81. & 12,726 . & $1,474.54$ & -60.5396 & 60.5396 &, 665.037 \\
\hline October & 1,556 . & 10. & 100. & 15,560 . & $1,373.022$ & 182.978 & 182.978 & $3,480.96$ \\
\hline November & 1,714 . & 11. & 121. & 18,854 . & $1,271.505$ & 442.4955 & 442.4955 & $95,802.3$ \\
\hline December & 781. & 12. & 144. & 9,372 . & $1,169.987$ & .388 .9871 & 388.9871 & $51,310.9$ \\
\hline TOTALS & 20,740 . & 78. & 650. & 120,293 . & & 0.0009 & $4,692.896$ & 955,499 . \\
\hline AVERAGE & $1,728.333$ & 6.5 & 54.1667 & $10,024.42$ & & 0.0001 & 391.0746 & $\overline{466,291.6}$ \\
\hline Nert period forecast & & & & & $1,068.469$ & (Bias) & (MAD) & (MSE) \\
\hline Intercept & $2,388.197$ & & & & & & Std err & 543.645 \\
\hline Slope & -101.5175 & & & & & & & \\
\hline & & & & & & & & \\
\hline
\end{tabular}

Sumber: QM for Windows (2015)

Berdasarkan perhitungan peramalan menggunakan QM for Windows (metode regresi linier) diperoleh hasil produksi gitar dengan menggunakan model APX500II atau $\mathrm{F}_{\text {Januari }}$ sebesar 1.068,469 unit dibulatkan menjadi 1.068 unit. Nilai MAD sebesar 391,0746 dibulatkan menjadi 391 dan MSE sebesar 246.291,6 dibulatkan menjadi 246.292.

\section{Simpulan}

Dari hasil penelitian yang telah dilakukan mengenai peramalan hasil produksi gitar model APX500II pada bulan Januari 2015 di PT. Yamaha Music Manufacturing Indonesia, menggunakan metode forecasting dan QM for Windows dapat disimpulkan bahwa:

1. Hasil produksi gitar model APX500II bulan Januari 2015 pada PT. Yamaha Music Manufacturing Indonesia menggunakan metode forecasting dan QM for Windows adalah sebesar 1.068,4695 unit, dibulatkan menjadi 1.068 unit.

2. Metode forecasting yang paling efektif untuk meramalkan hasil produksi gitar model APX500II bulan Januari 2015 pada PT. Yamaha Music Manufacturing Indonesia adalah metode regresi linier (linear regression method).

3. Nilai MAD dan MSE yang paling sesuai adalah MAD sebesar 391,0755 dibulatkan menjadi 391 dan MSE sebesar 246.291,6152 dibulatkan menjadi 246.292.

\section{Saran}

Dari hasil penelitian yang telah dilakukan di bagian produksi khususnya Departemen Accoustic Guitar 3 pada PT. Yamaha Music Manufacturing Indonesia, maka disarankan:

1. Sebaiknya perusahaan menggunakan metode regresi linier untuk meramalkan jumlah hasil produksi untuk periode yang akan datang berdasarkan nilai MAD dan MSE yang paling rendah.

2. Diharapkan metode peramalan yang digunakan lebih akurat dalam meramalkan hasil produksi sehingga gitar yang diproduksi sesuai dengan permintaan pasar, tidak terjadi kerugian akibat produksi yang berlebih dan semua produk dapat dipasarkan dengan baik.

\section{Daftar Pustaka}

Alfatiyah, Rini dan Mahyar. 2013. Perencanaan Produksi Minyak Telon Ukuran 100ml dengan Metode Time Series di PT. Merpati Mahardika. Jurnal Teknologi Vol.IX.No.25.Oktober 2013. 
Angelina, Vita dan Yudiastuti, Anni. 2013. Manajemen Dalam Konteks Indonesia. Kanisius. Yogyakarta.

Hasibuan, Malayu S.P. 2009. Manajemen Dasar, Pengertian dan Masalah. Bumi Aksara. Jakarta.

Kotler, Philip dan Kevin, Keller. 2009. Marketing Management. Prentice Hall. New York.

Lengkey, T.S., Kawet, Lotje dan Palandeng, Indrie.D. 2014. Perencanaan Produksi Produk Kecap dan Saos Pada CV. Fani Jaya. Fakultas Ekonomi dan Bisnis Jurusan Manajemen Universias San Ratulangi Mando Vol.2.No.3 Hal 1612-1621. Jurnal EMBA (September:2014).

Limakrisna, Nandan dan Susilo, Wilhelmus Hery. 2012. Manajemen Teori dan Aplikasi Dalam Bisnis. Mitra Wacana Media. Jakarta.

Ma'arif, Muhammad Syamsal dan Tanjung, Hendri. 2006. Manajemen Operasi. Cetakan Kedua. Penerbit PT. Grasindo, Anggota IKAPI. Jakarta.

Manullang, M. 2012.Dasar-Dasar Manajemen. Gajah Mada University Press. Yogyakarta.

Panjaitan, Lukas., Taringan, Gim \& Pengarepan Bangun. 2013. Peramalan Hasil Produksi Alumunium Batangan pada PT. Inalum dengan Metode Arima. Jurnal Saintia Matematika Vol 1. No. 1 (2013) PP 1-10.

Sarjono, Haryadi. 2012. Aplikasi Riset Operasi. Salemba Empat. Jakarta.

Sarjono, Haryadi. 2011. Peramalan Produk Air Mineral dengan Pendekatan Perbandingan Program Minitab and QM for Windows. Buletin Ekonomi Vol.9 No. 2 Desember 2011 hal. 83-170.

Satria, M. 2014. Step by Step Jago Main Gitar. Cemerlang Publishing. Jakarta.

Sofjan, Assauri. 2004. Manajemen Pemasaran (Dasar, Konsep dan Strategi). Cetakan ke Tujuh. Penerbit PT. Raja Grafindo Persada. Jakarta.

Sugiyono. 2010. Statistika untuk Penelitian. Alfabeta. Bandung.

Sujarweni, Wiratna.V. 2014. Metodologi Penelitian. Pusaka Baru Press. Yogyakarta.

Sunyoto, Danang. 2014. Dasar-Dasar Manajemen Pemasaran (Konsep, Strategi dan Kasus). CAPS. Yogyakarta. 